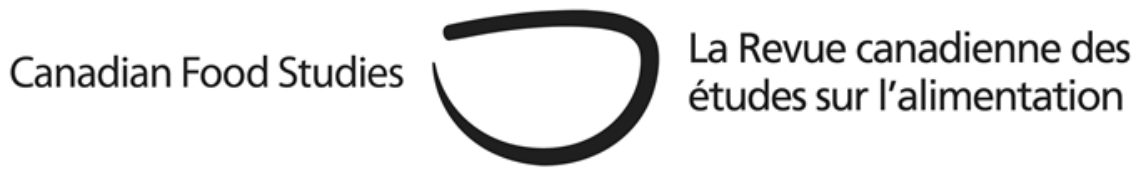

Original Research Article

\title{
Starving to be a student: The experiences of food insecurity among undergraduate students in Nova Scotia, Canada
}

\author{
Meredith Bessey ${ }^{a^{*}}$, Lesley Frank ${ }^{b}$, and Patricia L. Williams ${ }^{c}$ \\ ${ }^{a}$ Mount Saint Vincent University ${ }^{1}$ \\ ${ }^{\mathrm{b}}$ Acadia University \\ ${ }^{\mathrm{C}}$ Mount Saint Vincent University, FoodARC, Dalhousie University Healthy Populations Institute
}

\begin{abstract}
Household food insecurity (HFI) exists when access to food is inadequate or insecure due to financial constraints, and is an issue of increasing concern among postsecondary students who face barriers to food access due to precarious finances. The goal of the current study was to explore the experience of HFI among university students in Nova Scotia (NS), including barriers and facilitators, and potential policy solutions to the issue from the perspective of students. Twelve semi-structured, in-depth interviews were conducted with students experiencing HFI from across NS. Phenomenological analysis was undertaken, using Radimer's model of HFI as a theoretical framework. Key aspects of the experience of food insecurity in this sample included all four dimensions of Radimer's model of HFI: quantitative, qualitative, psychological, and social, along with other elements, such as emotions related to the experience, and a desire to be independent from parents. The main contributing factor to student's difficulties accessing food was inadequate and precarious finances. Students highlighted various coping mechanisms, such as utilizing food banks, budgeting their money, and buying food in bulk. This study is an important next step to a better understanding of the experience of student HFI in NS, building on previous quantitative research. Findings suggest that while the experience of HFI has many
\end{abstract}

\footnotetext{
${ }^{1}$ Meredith Bessey was a honours student in the Department of Applied Human Nutrition and a research assistant at the Food Action Research Centre (FoodARC), Mount Saint Vincent University when she completed this work. She is currently a PhD Student at the University of Guelph.
}

*Corresponding author: besseym@uoguelph.ca

DOI: $10.15353 /$ cfs-rcea.v7i1.375 
similarities with the experience in other populations, students experience tensions between independence and reliance on their family and have unique struggles related to government financial supports. The findings point to necessary policy changes related to student funding programs, and suggest that relying on campus food banks to solve the issue of HFI among students is inadequate.

Keywords: Student food insecurity; phenomenology; finances; student funding; health disparities

\section{Introduction}

Household food insecurity (HFI), defined as when access to food is inadequate or insecure due to financial constraints, is recognized as a critical public health issue in Canada (Tarasuk et al., 2016). Experiencing HFI places members of the household at risk for various negative physical and mental health outcomes, including diabetes, poor oral health, and depression (e.g., Alaimo et al., 2002; Gucciardi et al., 2009; Muirhead et al., 2009). HFI among post-secondary students is a growing area of interest. Studies to date suggest that approximately 35-40\% of post-secondary students on campuses in Nova Scotia (NS), Saskatchewan, Manitoba, and Newfoundland report experiencing HFI (Blundell et al., 2019; Entz et al., 2017; Frank, 2018; Olauson et al., 2018; Reynolds et al., 2018). These findings are consistent with those of a 2016 report by Meal Exchange, a national organization focused on campus food issues, which found an overall HFI prevalence of $39 \%$ across five Canadian campuses, with Dalhousie University in Halifax, NS, having the highest prevalence, at 46\% (Silverthorn, 2016). These prevalences are triple those that have been reported for all Canadians (Tarasuk et al., 2016). Additionally, NS has consistently had the highest prevalence of HFI of all Canadian provinces. For example, $17.5 \%$ of Nova Scotian households experienced HFI in 2012, compared to nearly $13 \%$ of households nationally (Tarasuk, Mitchell, \& Dachner, 2014).

Radimer and colleagues described, and Kendall and colleagues subsequently validated, four dimensions of food insecurity, at both the individual and household level - quantitative, qualitative, psychological, and social (Radimer et al., 1990; Kendall et al., 1995). This seminal work on individual and household food insecurity forms the basis of how HFI is measured in Canada and the United States (PROOF, 2018). The four dimensions are described in Table 1.

Table 1: Dimensions of food insecurity by Radimer et al., 1990.

\begin{tabular}{|l|l|l|}
\hline & Individual level & Household level \\
\hline Food Quantity & Insufficient intake & Food depletion \\
\hline Food Quality & Nutritional inadequacy & Unsuitable food \\
\hline
\end{tabular}




\begin{tabular}{|l|l|l|}
\hline $\begin{array}{l}\text { Psychological } \\
\text { Dimensions }\end{array}$ & Lack of choice, feelings of deprivation & Food anxiety \\
\hline Social Dimensions & Disrupted eating patterns & Food acquisition in socially unacceptable ways \\
\hline
\end{tabular}

Table adapted from Kendall et al., 1995.

Additionally, HFI exists on a spectrum of marginal, moderate, or severe (Tarasuk et al., 2016). Marginal HFI captures worrying about running out of food or limiting food selection due to limited financial resources. Moderate HFI can involve compromising the quality and/or quantity of the diet due to financial constraints, while severe HFI is defined as missing meals, reducing food intake, and/or going days without food (Tarasuk et al., 2016). Research indicates that university students experience HFI across the spectrum. To illustrate, data from Memorial University of Newfoundland indicated that $31.3 \%$ of students experiencing HFI were marginally food insecure, $48.7 \%$ were experiencing moderate $\mathrm{HFI}$, and $20.0 \%$ experienced severe $\mathrm{HFI}$ (Blundell et al., 2019). While students are arguably at risk of the negative health outcomes linked to HFI outlined above, they additionally are at risk of poor academic performance (e.g., Farahbakhsh et al., 2017; Olauson et al., 2018).

While various factors, such as lack of transportation, have been identified as barriers to food security for students (e.g., Frank, 2018), the most common barrier among students has been financial factors, such as cost of food, tuition fees, and inadequate income supports (Cheng, 2019; Entz et al., 2017; Frank, 2018; Maynard et al., 2018; Nugent, 2011; Silverthorn, 2016). Research to date has consistently demonstrated that international students, students who are employed, those who rely on government loans, those who are parents, or those who are of minority status are at higher risk of HFI (e.g., Blundell, et al., 2019; Entz et al., 2017; Frank, 2018; Olauson et al., 2018; Silverthorn, 2016; Reynolds et al., 2018).

Tuition rates in NS have consistently been among the highest in the country and continue to rise (Canadian Centre for Policy Alternatives, 2014; Statistics Canada, 2016), as do basic expenses, such as shelter and nutritious food (Newell et al., 2014). When students do not have sufficient funds for food, they use multiple coping mechanisms: working more, accessing a food bank, borrowing money or food from family or friends, using credit, delaying buying textbooks, finding free food events on campus, and/or stealing food (Bruening et al., 2016; Entz et al., 2017; Frank, 2018; Hughes et al., 2011; Maynard et al., 2018). Despite the well documented inadequacy of food banks and other charitable approaches to HFI, the food bank model has spread across nearly all Canadian post-secondary institutions (e.g., Silverthorn, 2016; Tarasuk et al., 2014). However, food banks are often utilized by a very small proportion (e.g., <10\%) of students experiencing HFI (Entz et al., 2017; Frank, 2018; Hughes et al., 2011; Olauson et al., 2018). The low utilization of campus food banks in the face of consistent reports of the high prevalence of HFI among students suggests that food banks are not meeting the needs of students experiencing HFI, and that longer term solutions are needed. 
While prevalence data tell us that HFI is common among Canadian students, it cannot capture the complexity of experiences of HFI. Only one qualitative study has been published exploring the experience of student HFI in the Canadian context (Maynard et al., 2018). This study involved interviews with 14 students who had compromised financial access to food. Findings indicate that participants normalized the experience of HFI while attending university, but also acknowledged the negative impacts that HFI had on their physical and mental wellbeing (Maynard et al., 2018). Considering the limited amount of qualitative research on this topic and given the broader context of rising food and tuition costs, it was important to learn more about the specific experience of student HFI, particularly in NS where prevalence is high, so as to better understand what contributes to students' experience and how to support university students to have better access to food.

\section{Methodology}

The current study utilized a qualitative approach and a phenomenological methodological framework. Phenomenological methodology is the process of understanding how a phenomenon, in this case, HFI, is experienced by the people it affects (Patton, 1990). In-depth interviews were conducted with undergraduate students in NS, in February to April 2017, in order to explore the phenomenon of HFI, to elucidate barriers and facilitators to food security, as well as to learn about potential policy solutions from the perspectives of students. Radimer's four dimensions of HFI were used as the theoretical framework that shaped the interview questions and analysis of data.

Ethical approval was obtained through the Mount St. Vincent University Research Ethics Board (REB), as well as through the REBs of St. Francis Xavier University and Cape Breton University; for the remaining universities in NS where the study was advertised, REB approval from MSVU was sufficient. Purposeful sampling was used to target undergraduate students who were at risk of HFI, consistent with previous literature (e.g., Frank, 2018; Silverthorn, 2016). Potential participants were recruited using posters on university campuses across NS, emails, social media posts, and word of mouth. Recruitment materials used the question "Do you struggle to afford the food you need and want?" in order to capture the interest of students who may be experiencing HFI. Participants were offered a \$20 gift card to a grocery store for their participation in the study. Potential participants were contacted by telephone to screen for eligibility in the study before being enrolled. To be eligible to participate, students needed to be experiencing marginal, moderate, or severe HFI, as assessed by the Household Food Security Survey Module, the tool used to monitor HFI in Canada (PROOF, 2018). Students also needed to indicate that they were supported by a student loan, employment, and/or a government program, and were living alone, with other students, and/or with their children. Of the 21 students who 
were screened for eligibility, twelve students met eligibility criteria for the study. All participants provided written informed consent.

Those eligible for the study were asked a set of semi-structured questions designed to explore Radimer's dimensions of HFI, which related to their typical eating habits, past or present experiences with HFI, ways they cope when accessing food is an issue, barriers and facilitators to their food access, and their perspectives on potential solutions to the issue of student HFI. The interview guide was adapted from Green-LaPierre and colleagues, who conducted a similar phenomenological study investigating HFI among low-income lone senior women in Halifax, NS (Green-LaPierre et al., 2012). Green-LaPierre's interview guide was modified to incorporate aspects pertaining to the specific experience of university students, based on published literature on HFI among students (e.g., Frank, 2018; Hughes et al., 2011; Maynard et al., 2018; Nugent, 2011). Sample interview questions can be found in Table 2.

Table 2: Selected interview questions

\begin{tabular}{|l|l|}
\hline Type of question & Question \\
\hline Icebreaker & What is your favourite meal to prepare and eat? What foods do you enjoy eating the most? \\
\hline Main & Walk me through a typical day for you... what do you normally eat? \\
\hline Main & $\begin{array}{l}\text { Has there ever been a time (since you have been a student in Nova Scotia) when you had } \\
\text { difficulty eating well? }\end{array}$ \\
\hline Probe & $\begin{array}{l}\text { What led up to your experience of having challenges in eating well/or getting enough nutritious } \\
\text { food? How did this experience begin for you? What were the circumstances or events that } \\
\text { triggered it? }\end{array}$ \\
\hline Main & $\begin{array}{l}\text { What is the biggest factor influencing YouR ability to access the foods you need and want? } \\
\text { What would help you the most to have better access to food? }\end{array}$ \\
\hline Summary & What have you learned from your experience with food insecurity (if applicable)? \\
\hline
\end{tabular}

Interviews were conducted in English, audio recorded, and transcribed verbatim. Participants were given the opportunity to review their transcripts and summary notes for accuracy and clarification. Each participant was assigned a pseudonym. Data analysis took place simultaneously with data collection and was undertaken with support of MaxQDA (Version 12.3.0) software (VERBI GmbH Berlin, 2017). Recruitment and screening continued until the sample size was reached, allowing previous interviews to inform questions and probes in subsequent interviews. A phenomenological approach to data analysis was used. Briefly, the steps of phenomenological analysis began with epoché, where the transcripts were read from an open and naïve perspective, with no judgements (Patton, 1990). Following this was phenomenological reduction, where the phenomenon in question was described in text, by coding and interpreting the transcripts, using Radimer's dimensions of HFI as a framework, but also remaining open to new ideas that arose from the interviews (Patton, 1990). Common codes were then grouped into categories, to develop a description of student HFI. Coding was an iterative process, with codes emerging and evolving as the interviews progressed. The last step 
was eidetic variation, where a structural description of the phenomenon was arrived at (Patton, 1990). This step involved both a description of the experience of student HFI, as well as elucidating the underlying factors that contribute to the experience. Data collection and analysis was ended after the twelfth interview, as no significant new themes were emerging and clear commonalities were apparent across the data (Creswell, 2014; Saunders et al., 2018). The first author (MB) led the coding process, with regular check-ins with the other authors, who supervised this research, to discuss coding structure and findings and to determine when data collection could cease.

The first author, who conducted the interviews, occupied the space as both "insider" and "outsider" on this project, which has been referred to as "the space between" (Dwyer \& Buckle, 2009). At the time of conducting this research, the interviewer was an undergraduate student in NS, sharing that commonality with the participants, however she was not a student who experienced food insecurity. There was a sense during the interviews that participants looked to the interviewer as a peer, however, and seemed honest and open during the interviews. This may not have been the case had the interviewer been a faculty member.

\section{Results}

\section{Demographic characteristics}

The majority of students were considered moderately food insecure $(n=10)$, with two participants being severely food insecure. Nine of twelve participants were single, two were common-law, and one was married. Two of twelve participants had children. Seven participants were students at Mount Saint Vincent University (MSVU), two were students at Dalhousie University, two were students at Acadia University, and one was a student at Nova Scotia College of Art and Design (NSCAD); MSVU, Dalhousie, and NSCAD are located in Halifax, NS, while Acadia is located rurally in Wolfville, NS. Two students were international students, while the remaining ten were Canadian citizens. Students varied from first to fifth year in their program, and were enrolled in a wide range of programs, from business administration, to sociology, to jewelry and metalsmithing.

\section{Student experience of HFI}

While Radimer's four dimensions of HFI were evident in the data, multiple other aspects of the experience of student HFI arose out of the interviews, including emotions relating to their experience and the physical and academic impacts of HFI. 


\section{Quantitative}

This aspect of HFI often presented as skipping meals, going hungry during the day, or reducing portion sizes to make the food they had last longer. For example, Jennifer noted that:

I feel like if I can make something stretch, whether it be like a loaf of bread, and I'll make half a sandwich versus a full sandwich to make it, stretch whatever I have, rather than go to a food bank and take away from somebody else.

Karen described eating smaller portions, such as a granola bar for breakfast and a piece of fruit for lunch, with a full meal at dinner, but felt that she was eating enough because she was not going to bed hungry. Olivia mentioned that when money was tight, she would not eat lunch and would eat less food overall.

\section{Qualitative}

More commonly described than quantitative experiences of HFI were qualitative experiences. All students made note of not eating the foods they wanted to, or of eating foods they knew were not "healthy" because it was all they could afford. Nicole noted: "I feel like I'm always making sure that I'm fed, maybe not always as much as I want to be, but what generally will get sacrificed I guess is like the nutritional aspect of the food."

Students described purchasing larger quantities of cheaper foods such as Minute Rice, pasta, and canned food, especially when they were on sale. Amanda stated that she and her family often eat less healthy options, just because they have to, not because they want to. Charlotte mentioned that because she could not afford to pay full price on many food items, she would have to buy produce that was wilted or going bad.

\section{Psychological}

Two common themes arose out of the data in relation to this dimension: lack of choice and preoccupation with their household food supply.

\section{Lack of choice}

Several students described feeling a lack of choice over what and how much they could eat, which limited the variety of their diet. Amanda explained that her daughter would often get tired of eating the same things. Henry shared that he would often get similar foods from the food bank, such as sweet potatoes, onions, and frozen meats, but he has found ways to diversify what he eats, such as by trading foods. Relatedly, students described almost a yearning for foods they 
used to be able to eat or afford, such as tuna, berries, smoothies, and Parmesan cheese. Olivia said "buying almonds should not be a luxury" but that foods like that were off limits given her financial constraints.

\section{Preoccupation with the food supply}

This involved constant thinking about where food and/or money for food will come from and planning when and how food will be acquired and prepared. Students planned their budget meticulously and/or checked prices at stores constantly to ensure their money would last. Along with this preoccupation came a feeling of anxiety and insecurity about obtaining food, planning meals, and eating the "right things." Olivia noted:

I don't know what it would feel like to go to the grocery store and not add everything up before I get to the till, so that way like, I just, I can't just put things in the cart and not worry.

\section{Social}

Many participants reported having to acquire food or money in ways they would prefer not to. For example, Henry recalled eating at a restaurant and not paying, because he was hungry and had no money to buy food. He did go back and pay later, because, as he described, he has "a conscience." Many participants also explained that they had to rely on their parents more than they would like. Heather, Jiao, and Jennifer said that they prefer not to ask their parents for money, but due to limited funds, parents sometimes were needed to fill gaps in their income. Beyond Radimer's social dimensions, students also described negative impacts on their social life. For example, Jennifer explained that:

...you're even insecure about going out with your friends, because like all your friends are going out and you don't want to be that one person who doesn't go out but they want to go to a restaurant, and then suddenly you have to figure out where that money comes from to cover it and stuff like that.

\section{Other Dimensions}

"People have it worse off than me." Many students vocalized feeling that others are worse off than them. Jennifer noted that:

I don't want to like go to Feed Nova Scotia or to a food bank, and look only out for myself, kind of thing, when I know, like, there's single parent families that are struggling, or like families, or like even just a single person that's also struggling. That I'm going to take away from them, 'cause like no one is supporting the food banks like they used to. 
Heather said that her situation is "not as extreme as other people, which I'm very fortunate for, but I definitely do feel hungry sometimes." Melissa shared that other people do not have the resources available to them that she has, and that she "...literally think[s] [the campus food bank]'s for students where they're piss poor broke, like I wouldn't even go in there. And I'm piss poor broke." Charlotte noted that she knows her situation is better than many other students who sometimes have to go hungry, while for her, she is primarily compromising the quality of her diet but getting adequate amounts of food.

\section{Wanting to be independent from parents}

Several students described the desire to be financially independent from their parents. Often, however, they had to rely on their parents, due to limited financial resources, and this caused internal tension. Nicole shared that because she is a mature student and she made the decision to return to school, “...it doesn't seem like even an option to be like going to my parents at all. I'm almost an adult now!" Melissa was no longer able to rely on her parents for support, and feels like she has exhausted all her resources and said: 'I'm just like hey, you're on your own, your loan comes in next week, budget it out. This is what you have to do, you're an adult."

\section{Emotions}

Students described a range of emotions in relation to their experience of food insecurity, including shame, embarrassment, sadness, self-blame, anger, frustration, and jealousy. As an example, Olivia explained that:

I can't talk to people about not having money, 'cause I'm embarrassed. So like, I don't know, I just make up excuses, like I need to go home and put [her son] to bed, or like, I don't have anyone to watch him tonight, but like, sometimes I do, I just, I can't tell people that because I don't want them to feel sorry for me.

\section{Physical and academic impacts of HFI}

Karen described feeling "crappy" and drained, due to the low quality of her diet. Jiao explained that she was often "so tired" and had no energy to eat. She also said that she sometimes felt sick, due to eating "too much" canned food, when she was used to eating "a lot" of fresh food before she started school. Four participants indicated weight change (loss or gain), which they related to their limited access to food. Additionally, multiple participants discussed how HFI had negative impacts on their academic performance. Karen explained that sometimes she had to skip class because she was so tired, and she also had to drop a class in order to free up some money to pay for food and other living expenses. Ahmed said that he would sometimes do his assignments 
while he waited for his work shift, but "...working has caused him to lose marks." He also noted that when he does not have enough food, he "...can't do very well in studying, to be honest."

\section{Coping mechanisms}

Students made use of a variety of coping mechanisms to try and have enough food to eat. However, the majority of students did not feel that using these coping mechanisms enabled them to eat in a way that they wanted or needed to. Common coping mechanisms included buying in bulk, budgeting and watching flyers/sales, using the campus food bank and other university services, borrowing food or money from family or friends, and eating free food at work or at events. For example, Melissa said, “... if I was like literally desperate and couldn't eat, like I would ask my friends, like my friends are all students, we've all [been in a similar situation before], yeah," suggesting that many other students can empathize with the situation she was in. Four of 12 students utilized either a campus or community food bank. Henry acquired 90-95\% of his food through a "fresh food bank" at a community organization. Less commonly mentioned coping mechanisms were using credit cards to buy food, picking up additional work, sharing cost of food with roommates, delaying eating or not eating, going to bed to avoid hunger, and drinking water in order to feel fuller.

\section{Barriers}

The most discussed barrier to food security was lack of money. Many factors contributed to this: inadequate or unexpectedly low student loans; high food cost, both in grocery stores and on campus; high costs of living, tuition and school-related materials; and tenuous and inconsistent employment. Some of these factors can be considered "income shocks," as will be discussed below. Multiple students mentioned having been or being in significant credit card debt or having "maxed out" lines of credit, impacting their ability to afford food. For some students, they had accumulated credit card debt before beginning school, but for many, this debt had been accrued since beginning their schooling. Amanda recounted that she pays the power and daycare bill and buys groceries before she pays her cell phone bill, "because on the pyramid of things that are important, it's the least important." While tuition cost was not specifically mentioned by many participants, those who did mention it felt that tuition was already too costly for many students and upcoming increases to tuition in NS would make it that much more difficult for students who are, as Laura stated, "just trying to get by already." Charlotte had a job on campus which was paid via honorarium, and she was only paid at the end of each semester - this made it increasingly difficult for her to afford groceries as the semester went on.

Most students also explained that lack of time was a barrier to food access, as it limited not only students' ability to grocery shop, but also to prepare and eat food. Nicole shared "mostly 
it's time for me... trying to manage to have the time to either like obtain the foods, so that's going to the grocery store, but then also, like cooking the foods properly." Amanda stated "I'm always on the go, I have lots of kids and my husband, and I work full time and do school full time, so I'm just always like, yeah I'm taking the fastest thing as possible." Other students, including Jennifer and Ahmed, echoed this and explained that their busy schedule, between work and school, limited their opportunities to eat.

Other less frequently mentioned barriers were transportation, lack of familiarity with stores in the area, limited options (especially for those students living in rural areas), inadequate resources or information about resources (e.g., food banks), not feeling welcome at the campus food bank, lack of food skills or access to ingredients, poor physical or mental health, alcohol and drug addictions, poor access to culturally appropriate foods, and not having family to rely on for support.

\section{Facilitators}

Students made note of various factors in their lives that facilitated their access to food and helped them eat better, albeit still experiencing HFI. Those students who had access to a car felt that it enabled their access to food, allowing them to travel to multiple stores to obtain the best prices. Several students identified support from friends, family, or a partner as a facilitator of food access. Some students explained that their parents helped them out financially, would buy groceries when they came to visit, or helped them obtain loan funding. Ahmed and Laura also shared cooking with their roommate, which they identified as a facilitator. Additionally, Ahmed indicated that having support from his community of friends was a facilitator: "I would say that community between me and my friends is very good. So, I would go and visit [my friend], to have that meal maybe. And he will do the same if he was having the same problem."

Several students identified having food skills or preparing meals in advance as a facilitator for their food access. It is important to note, however, that other students stated that while they are knowledgeable about preparing food and what a nutritious diet entails, they simply could not eat that way due to limited finances. Some students characterized themselves as being resourceful with the food they had and making good use out of a limited food supply. For example, Henry said that the tomatoes he gets from the food bank are often soft, but he will freeze them and utilize them in sauces or curries. He also had access to many spices at home, had extensive food preparation skills, and did his own sprouting.

Additionally, those students who utilized a food bank identified it as a facilitator to their food access. It is important to note here, however, that many of the students who did not use the food bank felt unwelcome or uncomfortable about using the service or felt they did not have adequate information about this service. Jiao and Heather also explained that prior to utilizing the food bank, they had felt uncomfortable or embarrassed about going there. Once they started 
using it, their comfort level increased. Nicole mentioned that sometimes her campus food bank had vegetables that she would never think to buy in store, so it has introduced her to new foods and diversified her diet. She also noted that the food bank is open 24 hours a day, which can be very useful when students are on campus late at night. Heather explained that the food bank on her campus often had fresh vegetables available that would give her the "nutritional balance" she feels she is lacking in her diet. Henry used a "fresh food bank" through a community organization he is part of; he identified the food bank at his university as "pretty grimy," suggesting his experience may be different if that was the only food bank he had access to.

Other less frequently mentioned facilitators were government financial support programs, access to a food market on campus, internet resources about eating on a budget, paid cooperative education, growing and hunting their own food, finding food on sale and/or access to more affordable stores, and living closer to a grocery store.

\section{Proposed solutions}

Students were asked about potential policy solutions to this issue; with most students, the interviewer suggested options (e.g., policy change in terms of student loans, a meal service program) and gathered their feedback on a number of ideas, as most participants needed some prompting in order to respond to this question. The three suggestions that resonated with students the most were a free campus meal program and/or improved campus food service, restructured student funding, and more accessible, welcoming food banks. Dalhousie University, in Halifax, NS, has a program that is operated at the student union called the Loaded Ladle (Loaded Ladle, n.d.), that serves free, plant-based meals multiple times a week to students. Henry and Laura, who were students at Dalhousie, felt that this program was a great offering, and Henry felt it should be part of the student union's role to provide food to students. Nicole, Charlotte, and Jennifer all felt that their campuses would benefit from a program such as the Loaded Ladle when this was described to them. Additionally, students felt that campus food service should be more accessible, in terms of hours of operation, and affordability for students.

In terms of government funding, many students suggested that it needs to be restructured to more realistically account for the cost of living for students. For example, Henry and Laura both mentioned that perhaps a non-repayable bursary should be given to specifically cover the cost of food. Heather shared that scholarships and student loans should not necessarily be based on your parents' financial situation. She said:

most times, like a lot of my friends, our parents aren't paying for our tuition, so it doesn't really matter what our parents are making because we're the ones that are coming up with the money. So, our financial need would be our income, not my parents', because my parents might not have that extra money. 
Jiao and Melissa suggested that their campus food bank be relocated to a more accessible area. Jiao also suggested to have signage in multiple languages to make it more accessible for international students on campus. Other suggestions students made were to change the language used, as they felt "food bank" had too much associated stigma, and to increase the hours to be more accessible to students with busy schedules.

Other proposed solutions were lower tuition fees, lower food costs in grocery stores or more discounts for students, a partnership between grocery stores and campus food banks, a Facebook group to share news about "good deals," and a mentorship program where new or international students can receive advice from more experienced students.

\section{Lessons learned}

Eight of twelve participants explained that they learned budgeting skills from their experiences of having difficulty accessing food. Amanda said that this is a skill that will continue to benefit her later in life. Many also noted that they did not realize the cost of food before coming to university, and they were now more knowledgeable about food prices. Many students mentioned that they had acquired food preparation skills and had learned to become resourceful and to look after themselves. Olivia shared that she has grown to feel more grateful for the things that she has, and Charlotte explained that she learned to not take money for granted.

\section{Discussion}

The current findings show that the experience of HFI among university students involves all four dimensions of Radimer's model and suggest that HFI among university students in NS is a complex issue, with many contributing factors and consequences. The commonalities among the existing Canadian qualitative research on this topic suggest that while the dynamics due to the provincial context differs, there are common threads that underlie the experience of HFI among students, at least in Ontario, Alberta, and NS (Maynard et al., 2018; Nugent, 2011). The experience among students appears to be one that is consistent with the experience of HFI among other low-income populations, including women, and specifically lone senior women (Hamelin et al., 2002; Williams et al., 2012; Green-Lapierre et al., 2012). However, unique aspects of the student experience also emerged, some of which were consistent with previous research (e.g., Maynard et al., 2018; Nugent, 2011; Silverthorn, 2016). Specifically, students experienced tension about being financially dependent on their parents, while desiring to be independent. This speaks to this time in life as a period of transition, where young adults are wanting to distance themselves from their parents at the same time that they are partially financially dependent on them. Students are also in a unique financial situation, in that many of them rely significantly on student loan payments, which are received in a lump sum at the beginning of one 
or both semesters. This is in contrast to other populations, who receive monthly income from work or government transfers. This method of dispersing payments may place students at increased risk of financial precarity and HFI.

This study found that, while participants identified many factors that contribute to student HFI, the most common was precarious and inadequate finances. Previously conducted qualitative research on this topic in Ontario and Alberta also identified finances as the major barrier to food access among students (Maynard et al., 2018; Nugent, 2011). This also echoes the results reported by Meal Exchange that identified financial factors as the major barrier to food security at five Canadian university campuses (Silverthorn, 2016). In the current study, budgeting and managing money was a major coping mechanism utilized by the majority of students, as was the case in qualitative research in other Canadian provinces (Maynard et al., 2018; Nugent, 2011) The theme of desiring financial independence was also consistent with other existing qualitative research, as was the coping mechanism of needing to borrow money from friends or family in the face of this desire (Maynard et al., 2018; Nugent, 2011).

In the current study, "income shocks" were present, primarily in the form of late student loan payments, student loan payments that were lower than expected, or less work hours than expected. These income shocks likely combined with existing low levels of financial resources, to create situations in which it was very difficult for students to afford food, as students did not have the resources to cope with these income shocks. The lump sum payments of student loans may also contribute to this vulnerability. This finding is consistent with previous research in Ontario (Maynard et al., 2018). Common income shocks included student loan payments coming in late, unplanned medical expenses, or the loss of a part-time job (Maynard et al., 2018). Income shocks have also been studied in other populations. Leete and Bania (2010) studied data from the Survey of Income and Program Preparation in the US and found that both level of income and negative income shocks were predictive of food insufficiency.

In addition, the idea that others are worse off than them is a common thread between the current research and previous qualitative research. Non-campus food bank users in Ontario explained that they did not feel like the "type" of person who should access a food bank, and students in Alberta were concerned with utilizing a service that they felt other people needed more (Maynard et al., 2018; Nugent, 2011). This feeling may impact students' willingness to access services like the food bank, as they feel that their situation is better than many other people in need. It is possible that this perception comes from the normalization of student HFI in our culture, as well as the perception that many university students are "rich kids" (Meal Exchange, n.d.; Maynard et al., 2018). If students are socialized to believe that it is normal to eat poorly and struggle while attending university, and that they are privileged to be in the position they are, it is logical that they would believe that other people, such as lone mothers or unemployed people, are having a harder time than them. Students who come from families with incomes of less than $\$ 50,000$ are also less likely to enroll in university than students from families with higher incomes (Statistics Canada, 2011). Therefore, it can be theorized that many university students have not experienced financial struggle prior to attending university, making 
them less likely to perceive themselves as poor. They may feel services such as food banks are for "poor people", which they may not identify with. While this warrants further study, more education may be needed to debunk the myth that HFI is a normal part of the student experience, a perception that both students and the public may hold.

While previous qualitative research in this area did not specifically explore facilitators or enablers to food access among students (Maynard et al., 2018; Nugent, 2011), this study identified increasing food skills and knowledge, seeking support from friends and family, and visiting food banks as facilitators to food access, making this a unique contribution of the current study. The role of friends and family was also found to be a facilitator of food access among lone senior women and women experiencing HFI in NS (e.g., Green-LaPierre et al., 2012; Williams et al., 2012), again suggesting that there are similarities between the experience of students and other populations experiencing HFI. Additionally, it is not clear if this is an experience that is more common in rural areas, such as in NS; this is an area where further research is necessary. Previous research has found that low-income women in NS considered food banks to play an important role in meeting emergency food needs, although they failed to meet their food needs in both quantity and quality (Williams et al., 2012). The students in this study similarly expressed that food banks were important for emergencies, however, compared to the experiences of lowincome women, food banks allowed the students to eat healthier than they would have otherwise because of the fresh vegetables and fruits they received (Williams et al., 2012). This raises the question of whether campus food banks and community food banks differ in terms of the quality of foods they provide or whether students perceive the food bank in a different way than do other populations.

Universities in NS and across Canada should be concerned about HFI in their student populations, as it is an issue that has the potential to impact the physical and mental health, quality of life, and productivity and retention of their students (e.g., Entz et al., 2017; Frank, 2018). Institutions of higher education support the wellness of their students through student services. However, while student-run initiatives have been created to address the food needs that arise while at university due to financial constraint, neither institutions nor governments have addressed the structural causes of student HFI. Governments have decreased post-secondary funding over time, leading to tuition increases in order to maintain the financial sustainability of NS universities (Students Nova Scotia, 2013). Increases in tuition, increased cost of living, a consistently low minimum wage, and inadequate student loans all have the potential to further exacerbate HFI among university students in our province (e.g., Newell et al., 2014; Statistics Canada, 2016). There is a significant mismatch between the cost of education and student's ability to pay, which, as this research demonstrates, impacts students' ability to purchase and eat nutritious food with significant implications for health. Why this mismatch exists is complicated and is likely outside of the scope of this specific paper, but is an important area for future research and policy considerations.

\section{Study limitations}


This study is the first to investigate student HFI in NS using a qualitative research approach, making an important contribution to the growing body of research on this topic. However, not all campus communities were included in this study. The majority of participants lived in Halifax, the urban centre of the province, meaning that the experiences of students living in more rural areas may not have been fully reflected in this study. Additionally, only undergraduate students were interviewed for this study; future research could investigate the experiences of graduate students, as it may be substantively different from that of undergraduates.

\section{Conclusions}

In the context of increasing tuition fees in NS and in combination with data on the prevalence of student HFI across Canada, the current findings are concerning. University students are already struggling to afford food and the situation may worsen, as expenses increase and food prices are forecasted to continue to increase (Dalhousie University and University of Guelph, 2019). The findings of this study suggest that relying on campus food banks to address the problem of student HFI is inadequate. Many factors contribute to HFI among university students, but precarious and inadequate finances were identified as the main contributing factor. Therefore, policies aimed at improving student funding and reducing the cost of higher education to address this issue should be a focus, so university students in Canada do not have to starve to be a student. As Dachner and Tarasuk (2018) note, tackling HFI is an essential goal of a national food policy for Canada. Addressing HFI among post-secondary students must be considered a key part of this goal. Additionally, it is important that there is a system in place to monitor and track student HFI over time, in order to ensure that policy changes are having meaningful impacts on the lives of students.

This study is an important step towards a better understanding of the experience of HFI among university students in NS and suggests that students are under unique financial and personal pressures. Potential areas for future research include exploring HFI among graduate students and early career professionals, and to explore specific policy levers, such as alternative student funding structures like educational grants or affordable food service models that could be utilized to improve student HFI in NS and Canada.

Acknowledgements: The authors would like to thank the participants in this research, for being so open and honest about their experiences. We would also like to thank those who supported us in recruiting on various Nova Scotia campuses. We also acknowledge the in-kind contributions 
and funding support for research expenses from FoodARC through the Voices for Food Security in NS project, which was funded by the Nova Scotia Department of Health and Wellness.

\section{References}

Alaimo, K., Olson, C.M., \& Frongillo, E.A. (2002). Family food insufficiency, but not low family income, is positively associated with dysthymia and suicide symptoms in adolescents. Journal of Nutrition, 132(4), 719-725. DOI: 10.1093/jn/132.4.719

Blundell, L., Mathews, M., Bowley, C., \& Roebothan, B. (2019). Determining student food insecurity at Memorial University of Newfoundland. Canadian Journal of Dietetic Practice \& Research, 80(1), 14-21. DOI: 10.3148/cjdpr-2018-026

Bruening, M., Brennhofer, S., van Woerden, I., Todd, M., \& Laska, M. (2016). Factors related to the high rates of food insecurity among diverse, urban college freshmen. Journal of the Academy of Nutrition \& Dietetics, 116(9), 1450-1457. DOI: 10.1016/j.jand.2016.04.00

Canadian Centre for Policy Alternatives. (2014). Infographic: an education in inflation 2014. https://www.policyalternatives.ca/publications/facts-infographics/infographic-educationinflation-2014

Cheng, N. (2019). Analysis of food insecurity solutions and evaluation methods on Colorado campuses. (Unpublished honours thesis). University of Colorado at Boulder, USA.

Creswell, J. W. (2014). Research design: Qualitative, quantitative, and mixed methods approaches (4th ed.). Thousand Oaks, CA: SAGE Publications.

Dachner, N. \& Tarasuk, V. (2018). Tackling household food insecurity: An essential goal of a national food policy. Canadian Food Studies, 5(3), 230-247. DOI: 10.15353/cfsrcea.v5i3.278

Dalhousie University and University of Guelph. (2019). Canada's food price report 2019. https://cdn.dal.ca/content/dam/dalhousie/pdf/management/News/News\%20\&\%20Events/ Canada\%20Food\%20Price\%20Report\%20ENG\%202019.pdf

Dwyer, S.C., \& Buckle, J.L. (2009). The space between: On being an insider-outsider in qualitative research. International Journal of Qualitative Methods, 8(1), 54-63. DOI: $10.1177 / 160940690900800105$

Entz, M., Slater, J., \& Desmarais, A.A. (2017). Student food insecurity at the University of Manitoba. Canadian Food Studies, 4(1), 139-159. DOI: 10.15353/cfs-rcea.v4i1.204

Farahbakhsh, J., Hanbazaza, M., Ball, G.D., Farmer, A.P., Maximova, K., \& Willows, N.D. (2017). Food insecure clients of a university-based food bank have compromised health, dietary intake and academic quality. Nutrition \& Dietetics, 74(1), 67-73. DOI: 10.1111/1747-0080.12307

Frank, L. (2018). "Hungry for an education": Prevalence and outcomes of food insecurity among students at a primarily undergraduate university in rural Nova Scotia. Canadian Journal of Higher Education, 48(2), 109-129. DOI: 10.7202/1057106ar 
Green-LaPierre, R.J., Williams, P.L., Glanville, N.T., Norris, D., Hunter, H.C., \& Watt, C.G. (2012). Learning from "knocks in life": Food insecurity among low-income lone senior women. Journal of Aging Research, 2012(450630), 1-11. DOI: 10.1155/2012/450630

Gucciardi, E., Vogt, J.A., DeMelo, M., \& Stewart, D.E. (2009). Exploration of the relationship between household food insecurity and diabetes in Canada. Diabetes Care, 32(12), 22182224. DOI: $10.2337 / \mathrm{dc} 09-0823$

Hamelin, A.M., Beaudry, M., \& Habicht, J.P. (2002). Characterization of household food insecurity in Quebec: Food and feelings. Social Science \& Medicine, 54(1), 119-32. DOI: 10.1016/S0277-9536(01)00013-2

Hughes, R., Serebryanikova, I., Donaldson, K., \& Leveritt, M. (2011). Student food insecurity: The skeleton in the university closet. Nutrition \& Dietetics, 68(1), 27-32. DOI: 10.1111/j.1747-0080.2010.01496.x

Kendall, A., Olson, C.M., \& Frongillo, E.A. (1995). Validation of the Radimer/Cornell measures of hunger and food insecurity. Journal of Nutrition, 125(11), 2793-801. DOI: $10.1093 / \mathrm{jn} / 125.11 .2793$

Leete, L., \& Bania, N. (2010). The effect of income shocks on food insufficiency. Review of Economics of the Household, 8(4), 505-526. DOI: 10.1007/s11150-009-9075-4

Loaded Ladle. (n.d.). Current operations. https://loadedladle.com/current-operations/

Maynard, M.S., Meyer, S.B., Perlman, C.M., \& Kirkpatrick, S.I. (2018). Experiences of food insecurity among undergraduate students: "You can't starve yourself through school". Canadian Journal of Higher Education, 48(2), 130-148. DOI: 10.7202/1057107ar

Meal Exchange. (n.d.). 10 myths about student poverty. http://mealexchange.com/images/10\%20Myths\%20About\%20Student\%20Poverty.pdf

Muirhead, V., Quiñonez, C., Figueiredo, R., \& Locker, D. (2009). Oral health disparities and food insecurity in working poor Canadians. Community Dentistry and Oral Epidemiology, 37(4), 294-304. DOI: 10.1111/j.1600-0528.2009.00479.x

Newell, F.D., Williams, P.L., \& Watt, C.G. (2014). Is the minimum enough? Affordability of a nutritious diet for minimum wage earners in Nova Scotia (2002-2012). Canadian Journal of Public Health, 105(3), e158-e165. DOI: 10.17269/cjph.105.4322

Nugent, M. (2011). Journeys to the food bank: Exploring the experience of food insecurity among postsecondary students (Master's thesis). University of Lethbridge, Canada. http://hdl.handle.net/10133/3228

Olauson, C., Engler-Stringer, R., Vatanparast, H., \& Hanoski, R. (2018). Student food insecurity: Examining barriers to higher education at the University of Saskatchewan. Journal of Hunger and Environmental Nutrition, 13(1), 19-27. DOI: 10.1080/19320248.2017.1393365

Patton, M.Q. (1990). Qualitative evaluation and research methods (2 ${ }^{\text {nd }}$ ed.). Newbury Park: Sage Publications, Inc. 
PROOF. (2018). Household food insecurity in Canada: A guide to measurement and interpretation. Research to identify policy options to reduce food insecurity (PROOF). https://proof.utoronto.ca/resources/measurement-guide/

Radimer, K.L., Olson, C.M., \& Campbell, C.C. (1990). Development of indicators to assess hunger. Journal of Nutrition, 120(Suppl 11), 1544-1548. DOI: 10.1093/jn/120.suppl_11.1544

Reynolds, E., Johnson, C., Jamieson, J.A., \& Mawhinney, H. (2018). Prevalence and correlates of food insecurity among students attending a small, rural Canadian university. Canadian Journal of Dietetic Practice \& Research, 79(3), 125-128. DOI: 10.3148/cjdpr-2018-004

Saunders, B., Sim, J., Kingstone, T., Baker, S., Waterfield, J., Bartlam, B., Burroughs, H., \& Jinks, C. (2018). Saturation in qualitative research: Exploring its conceptualization and operationalization. Quality \& Quantity, 52(4), 1893-1907. DOI: 10.1007/s11135-0170574-8

Silverthorn, D. (2016). Hungry for knowledge: Assessing the prevalence of student food insecurity on five Canadian campuses. http://mealexchange.com

Statistics Canada. (2011). Postsecondary education participation among underrepresented and minority groups. Ottawa, ON: Statistics Canada. http://www.statcan.gc.ca/pub/81-004x/2011004/article/11595-eng.htm\#a

Statistics Canada. (2016). Table B.2.9: Average undergraduate and graduate university tuition fees, full-time Canadian students, Canada and provinces, 2009-2010 to 2015-2016. Ottawa, ON: Statistics Canada. http://www.statcan.gc.ca/pub/81-582x/2016001/tbl/tblb2.9-eng.htm

Students Nova Scotia. (2013). Fairness in Nova Scotia university funding: Who pays and how much?: http://studentsns.ca/wp-content/uploads/2013/05/SNS-Funding-Report-Final-ForDistribution.pdf

Tarasuk, V., Dachner, N., Hamelin, A.M., Ostry, A., Williams, P., Bosckei, E., Poland, B., \& Raine, K. (2014). A survey of food bank operations in five Canadian cities. BMC Public Health, 14, 1234. DOI:_10.1186/1471-2458-14-1234

Tarasuk, V., Mitchell, A., \& Dachner, N. (2014). Household food insecurity in Canada, 2012. PROOF. http://proof.utoronto.ca

Tarasuk, V., Mitchell, A., \& Dachner, N. (2016). Household food insecurity in Canada, 2014. PROOF. http://proof.utoronto.ca

VERBI GmbH Berlin. (2017). MaxQDA. Berlin, Germany: Verbi GmbH Berlin.

Williams, P.L., MacAulay, R., Anderson, B., Barro, K., Gillis, D.E., Johnson, C., Langille, L., Moran, S., \& Reimer, D.E. (2012). "I would have never thought that I would be in such a predicament": Voices from women experiencing food insecurity in Nova Scotia, Canada. Journal of Hunger and Environmental Nutrition, 7(2-3), 253-70. DOI:

10.1080/19320248.2012.704740 